\title{
The Strange M. Proust, edited by André Benhaïm
}

\section{Geneviève Henrot Sostero}

\section{(2) OpenEdition}

\section{Journals}

\section{Edizione digitale}

URL: http://journals.openedition.org/studifrancesi/7008

DOI: 10.4000/studifrancesi.7008

ISSN: 2427-5856

\section{Editore}

Rosenberg \& Sellier

\section{Edizione cartacea}

Data di pubblicazione: 1 septembre 2010

Paginazione: 400

ISSN: 0039-2944

\section{Notizia bibliografica digitale}

Geneviève Henrot Sostero, «The Strange M. Proust, edited by André Benhaïm», Studi Francesi [Online],

161 (LIV | II) | 2010, online dal 30 novembre 2015, consultato il 08 janvier 2021. URL: http:// journals.openedition.org/studifrancesi/7008 ; DOI: https://doi.org/10.4000/studifrancesi.7008

Questo documento è stato generato automaticamente il 8 janvier 2021.

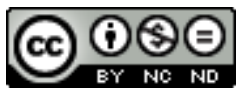

Studi Francesi è distribuita con Licenza Creative Commons Attribuzione - Non commerciale - Non opere derivate 4.0 Internazionale. 


\title{
The Strange M. Proust, edited by André Benhaïm
}

\author{
Geneviève Henrot Sostero
}

\section{NOTIZIA}

The Strange M. Proust, edited by André BENHAÏM, London, Modern Humanities Research Association and Maney Publishing, 2009 («Legenda»), pp. 142.

1 Dedicato alla memoria del noto studioso proustiano Malcolm Bowie, mancato nel 2007, il volume comprende, nei dieci interventi pronunciati al convegno internazionale di Princeton (22-23 aprile 2006), l'ultimo contributo orale della sua breve vita (1944-2007).

2 L'àmbito oggetto di approfondimento riguarda sia l'opera proustiana in sé che la sua ricezione. Di particolare interesse per l'incontro volevano essere gli aspetti tuttora sorprendenti o addirittura "strani" della Recherche, aspetti che continuano a sollecitare il lettore contemporaneo. Dal regime parzialmente autobiografico dell'opera al genere prescelto e plasmato, dalle mille e una gemma di romanzi laterali incompiuti agli eventi più imprevedibili che vengono narrati, l'estraneità dell'opera coinvolge anche i suoi paradigmi più fondamentali, quali la gestione complessa e a volte contraddittoria del tempo, le intersezioni spaziali, le convergenze diegetiche. A maggior ragione se, con la "giusta distanza", si variano le prospettive di osservazione (fenomenologiche, psicologiche, filosofiche, antropologiche o musicologiche). A maggior ragione ancora se si sondano falde più sotterranee, più occulte o più sottili del testo.

3 Estraniante risulta, per esempio, il sentimento dell'io proustiano che si sente sfrattato dalla propria dimora corporea (David ELLISON, The Disquieting Strangeness of M. P., pp. 12-22). Stuzzicanti, le molteplici metamorfosi subite dal suo pensiero nei commenti di diversi filosofi contemporanei, da Sartre a Ricœur (Anne sIMON, The Formalist, the Spider and the Phenomenologist: Proust in the Magic Mirror of the Twentieth Century, pp. 23-35). Inaspettato, il sintagma che costruisce un nome proprio che sembrava non dover mai venire a galla, e che, in effetti, viene subito smentito con ironia (Eugène NICOLE, "Quel 
Marcel!» (And Other Oddities of the Narrator's Designations in "À la recherche du temps perdu"), pp. 36-44). Quanto alla tanto discussa judaité espressa nel romanzo (vedasi, last but not least, lo scontro Brami/Piperno in chiusura del «Bulletin d'informations proustiennes», n. 39): Brami, nel romanzo, smentendo la biografica provenienza materna dell'ebraismo proustiano, sostiene che l'eredità religiosa venga trasmessa con maggiore autorevolezza dal padre spirituale del narratore, ovvero Swann (Jo-seph BRAMI, Strange Jewishness: Essay on the Treatment of Jewish Identity in Proust, pp. 45-56). In contesti significativi, benché fugaci, alcune comparse di lontana provenienza geografica fanno da cartina di tornasole alla concezione dell'esotismo e dello spaesamento secondo Proust (André BENHAїM, Proust's Singhalese Song (A Strange Little Story), pp. 57-70). Avvalendosi delle poche comparse di Leonardo da Vinci nella Recherche, Raymonde COUDERT ipotizza, con A Proustian "Metterza", pp. 71-85, la possibile simmetria della trinità generazionale (sant'Anna-Vergine-bambin Gesù) raffigurata dalla Metterza leonardesca con un'altra trinità proustiana (nonna-madre-figlio) spesso congelata in quadri descrittivi in momenti di alta emozione della Recherche. Non finisce di sorprendere neppure la varietà di materiali e prestiti accolti e intrecciati nel tessuto chiné dell'opera: come indica Christie MACDONALD (Da capo: Accumulations and Explosions, pp. 86-100), l'esperienza della lettura richiede al lettore (in questo caso Proust medesimo) una particolare capacità di estraniamento per calarsi nella visione altrui. In effetti, Proust testimonia a più riprese il suo interesse per lo sguardo sorprendentemente nuovo che concede, sul mondo contemporaneo, l'arte (allora) nuova della fotografia (Michael wood, Other Eyes: Proust and the Myths of Photography, pp. 101-111). Un ulteriore effetto di strana sorpresa si sprigiona dai numerosi paradossi coltivati dall'autore. Quello che s'instaura tra Verità e Giustizia rivela, per esempio, come tanti altri, una conturbante concezione della morale (Antoine compaGNon, Truth and Justice, pp. 112-124). Infine, con Reading Proust between the Lines (pp. 125-134), Malcolm BowIE, discostandosi da una tradizione critica affezionata all'analisi del brano, ripercorre l'opera con occhio da geometra in cerca di sovrapposizioni che si richiamano anche a grandi distanze testuali.

Una bibliografia collettiva e un indice dei nomi chiudono il volume. 